\title{
Topical Collection on Women's Mental Health during the Covid-19 Pandemic
}

Special Guest Editor: Anita Riecher-Rössler

Published online: 7 December 2020

(C) Springer-Verlag GmbH Austria, part of Springer Nature 2020 